\title{
Development of positive socialization and dialogic speech in older preschoolers
}

\author{
Maria Romanova ${ }^{1 *}$, Tatiana Fedorenko ${ }^{2}$, Tatiana Savenkova $^{1}$, and Ekaterina Ryabova $^{3}$ \\ ${ }^{1}$ Moscow City University, Institute of Pedagogy and Psychology of Education, Moscow, Russia \\ ${ }^{2}$ Sakhalin State University, Department of Theory and Methods of Training and Education, Yuzhno- \\ Sakhalinsk, Russia \\ ${ }^{3}$ Abay Kazakh National Pedagogical University, Institute of Pedagogy and Psychology, Department \\ of Professional Training Educational Program "Elementary education", Almaty, Kazakhstan
}

\begin{abstract}
The article deals with the problem of positive socialization of children in the course of dialogic speech development. At the early stages, the effectiveness of the socialization process of the individual largely depends on the development of skills and abilities of oral speech, in particular dialogic speech. The study aimed to develop the content, organization form, personal enhancement methods, and methodology of dialogic speech advancing as a factor of positive socialization of the child's personality during preschool age. Based on the purpose of the study, a methodology has been developed which proves that the level of positive socialization depends on the development of skills and abilities of dialogic speech. The proposed program and methodology focus not only on the ability to build a dialogue in question-and-answer form but also on the ability of optimal listening (to hear the interlocutor, to make replicasresponses according to what was heard, to change the course of the conversation without deviating from its main topic), as well as etiquette and behavioral skills. During classes on the "Program on positive socialization and development of dialogic speech in older preschool children" developed based on the proposed methodology, along with dialogic speech, children develop important components of emotional intelligence: the ability to adequately express their own emotions; understand the emotions and motives of other people's behavior; improve the skills of using nonverbal means (facial expressions, gestures, etc.) of communication in the course of dialogue; as well as to enhance the parameters that characterize positive socialization, such as self-esteem, independence, and successfulness. The program has passed an empirical test, which confirmed its effectiveness.
\end{abstract}

Keywords: positive socialization, dialogic speech, speech development.

\footnotetext{
*Corresponding author: romanovamarie@mail.ru
} 


\section{Introduction}

Since the publication of the work of L.S. Vygotsky "History of the development of higher mental functions", the core statement has been established in Russian child psychology and pedagogy that the child's mastery of social experience and behavior is mainly due to the development of speech. For contemporary preschool pedagogy, it remains an indisputable fact that at the early stages of socialization of the individual, the effectiveness of this process largely depends on the development of oral speech, in particular, dialogic speech. The authors consider the development of dialogic speech as one of the most important factors of positive socialization of the personality of an older preschool child.

The methodology of speech and competencies development of future and current teachers is constantly being improved and updated with new knowledge due to the achievements of preschool didactics, psychology, psycholinguistics, and sociolinguistics. In contemporary methodological systems, the emphasis is not only on the ability of children to build a dialogue in question-and-answer form but also on the ability to optimal listening (to hear the interlocutor, to make replicas-responses according to what was heard, to change the course of the conversation without deviating from its main topic), as well as etiquette and behavioral skills.

Socialization is understood as the development of a wide range of social competencies in a child that are fundamentally important for adaptation to the social environment and social life. The main functions of the socialization process of a preschool child are assimilation and reproduction of social experience, as well as social creativity as a condition for future social changes (E.N. Volkova, T.V. Vereitinova, I.V. Volkova, O.S. Mikhalyuk [1], E. Šaras, L. Perez-Falkner, [2], J.G. Smetana, J., Robinson, W.M. Rote, [3]).

\section{Methods}

The assessment of the positive socialization levels of older preschool children was carried out using the following parameters: emotional intelligence, self-esteem, independence, and social successfulness. The assessment was carried out using the observation method in combination with the expert method. To diagnose the development level of dialogic speech, the method of M.M. Alekseeva and V.I. Yashina was used [4]. This method allowed assessing the child's sociability, communication style (expressiveness, the presence of nonverbal means, the use of emotionally expressive words and expressions, as well as intonation coloring of phrases); features of the presentation of the material (logical coherence in text passages, the appropriateness of the use of lexical means, the correctness of selected grammatical constructions, and the syntactic variety of sentences used), as well as the degree of child's independence in performing tasks.

The empirical study was conducted based on the Moscow State Educational Institution "School No. 2103". The study involved 65 children of senior preschool age: 32 children in the control group and 33 in the experimental group.

Diagnostics of the positive socialization and development levels of dialogic speech of older preschool children was carried out in the experimental and control groups before and after the implementation of the experimental program.

The results of diagnostics of the positive socialization and dialogic speech development levels in older preschool children in both groups at the initial diagnostic stage are shown in the diagram presented in Figure 1. 


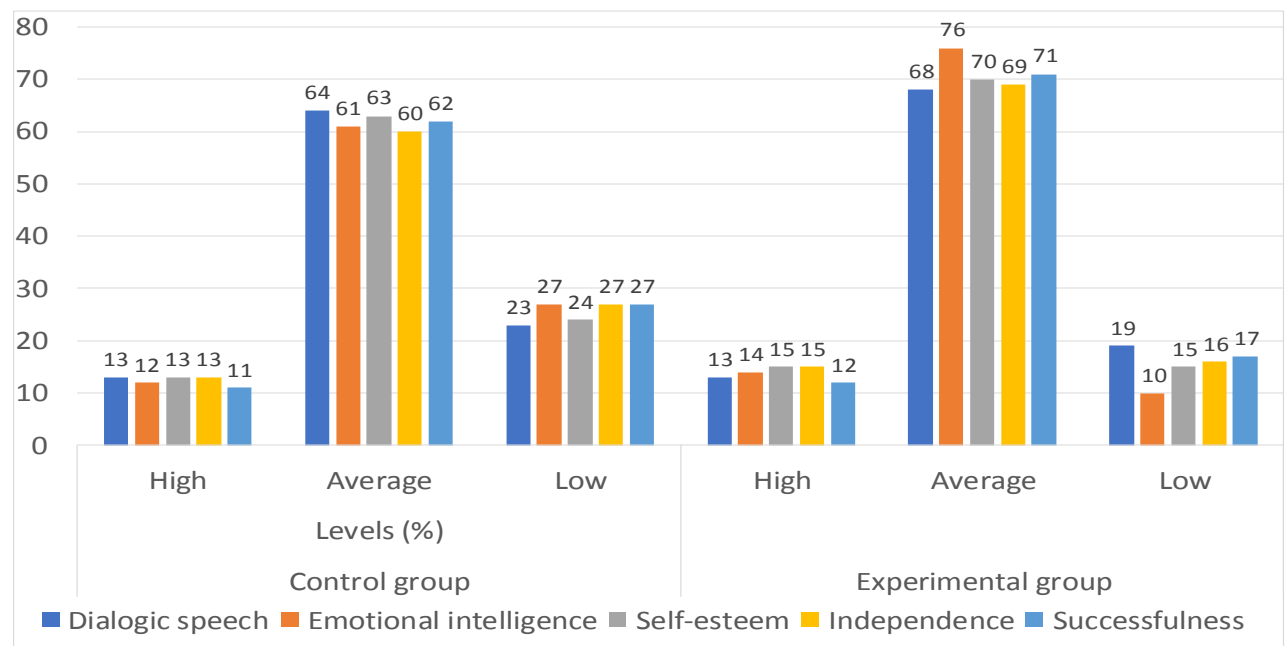

Fig. 1. Results of diagnostics of positive socialization and development level of dialogic speech of children of senior preschool age based on the results of initial diagnostics.

As can be seen from the diagram, the results of the initial diagnostics of children in the experimental and control groups were almost identical that indicated equal development levels of children in the experimental and control groups before the beginning of the formative stage of the study.

After completing the diagnostic stage of the study, a program of positive socialization based on the development of dialogic speech in older preschoolers was implemented in the experimental group. At the same time, the control group of older preschoolers who participated in the study worked according to the traditional model for preschool educational organizations, which also solved the problems of positive socialization and development of dialogic speech based on the standard development program.

When developing the program, the authors used the research results on the process of positive socialization of the individual, whose foundation was social intelligence (A.I. Savenkov [5, 6], S.I. Karpova, E.I. Sukhova [6], Z.V. Parkhimovich [7], T.D. Savenkova [7, 8], M. Anwer, N.I. Malik, A. Maqsood, G. Rehman [9], etc.), as well as scientific developments in the field of theory and methods of speech development of older preschool children (E.V. Aladatova [10], T.I. Babaeva [11], O.A. Bizikova [12]. B.B. Gerbova [13], T.G. Fedorenko [14], J.D. Mayer and P. Salovey [15]).

The purpose of the developed program was to create conditions for positive socialization of older preschool children by developing their dialogic speech. In the course of selecting methodological materials, the following goals were set:

- developing a set of special tasks that would allow gradually and consistently complicating and stimulating speech communication, developing social contacts of older preschoolers,

- creating a system of consistent training of older preschool children in the norms and rules of dialogic speech-making,

- creating conditions that would activate independent, spontaneous communication of older preschool children with their peers and adults,

- creating conditions for improving the social status of a child in a group of peers by adjusting their self-esteem and stimulating speech contacts with peers and adults,

- promoting the development of children's dialogic speech by creating conditions for awareness of success situations in the course of speech interaction with peers and adults. 
The program included special classes on speech development, usually carried out in a pre-school educational institution. During these classes, teachers purposefully worked on the task of positive socialization of children in the course of education, training, and developing their speech culture, forming skills and abilities to dialogic speech-making. It was supposed to use traditional and innovative forms of organizing classes and methodological techniques that were usually used when working with older preschoolers, namely, story-role-playing games; dramatization games; picture-based stories; memorizing and reciting poems-dialogues; playing dramatizations, participating in performances, discussing children's books and cartoons. The program included specially selected and authorial tasks and exercises aimed at step-by-step development of dialogical units, such as "motivation - response to the motivation", "question - answer", and "message - response to the message". When performing such tasks and exercises, teachers involved in the experiment paid equal attention to the development of children's general communication skills, as well as basic parameters of social intelligence (social knowledge, social intuition, adequate expression of their own emotions, and understanding of other people's emotions, self-control of their speech and behavioral responses, etc.). No less attention was paid to the formation and development of general linguistic knowledge, skills, and abilities.

\section{Results}

The results obtained during the final diagnostics have shown a noticeable increase in the number of children in the experimental group with a high and average level of development of assessed parameters. Besides, the percentage of preschool children with a low level of the studied parameters decreased in the experimental group. At that, children with an average level of dialogic speech development still made up the largest percentage in both groups.

The indicators dynamics of the experimental group are shown in Figure 2.

Analyzing the data obtained as a result of the initial and control diagnostics of the control group respondents, it can be noted that the percentage of children with a high level of dialogic speech development increased slightly, as well as the percentage of respondents with an average level of dialogic speech development and positive socialization had shown little progress. There were neither obvious positive nor negative trends in the parameters of positive socialization and the development level of dialogic speech of older preschool children from the control group. The dynamics of indicators of the control group are shown in Figure 3. 


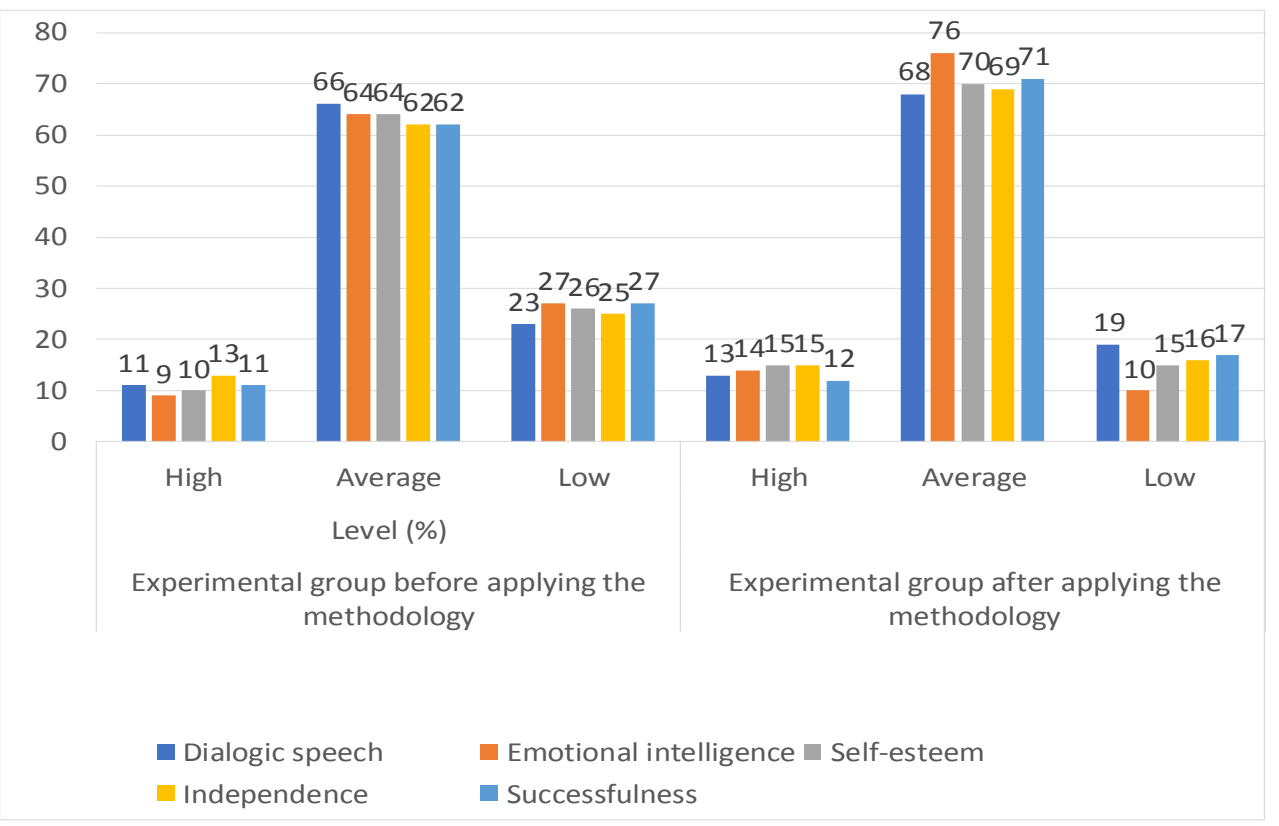

Fig. 2. Dynamics of positive socialization and levels of dialogic speech development in older preschool children in the experimental group (initial and final diagnostics).

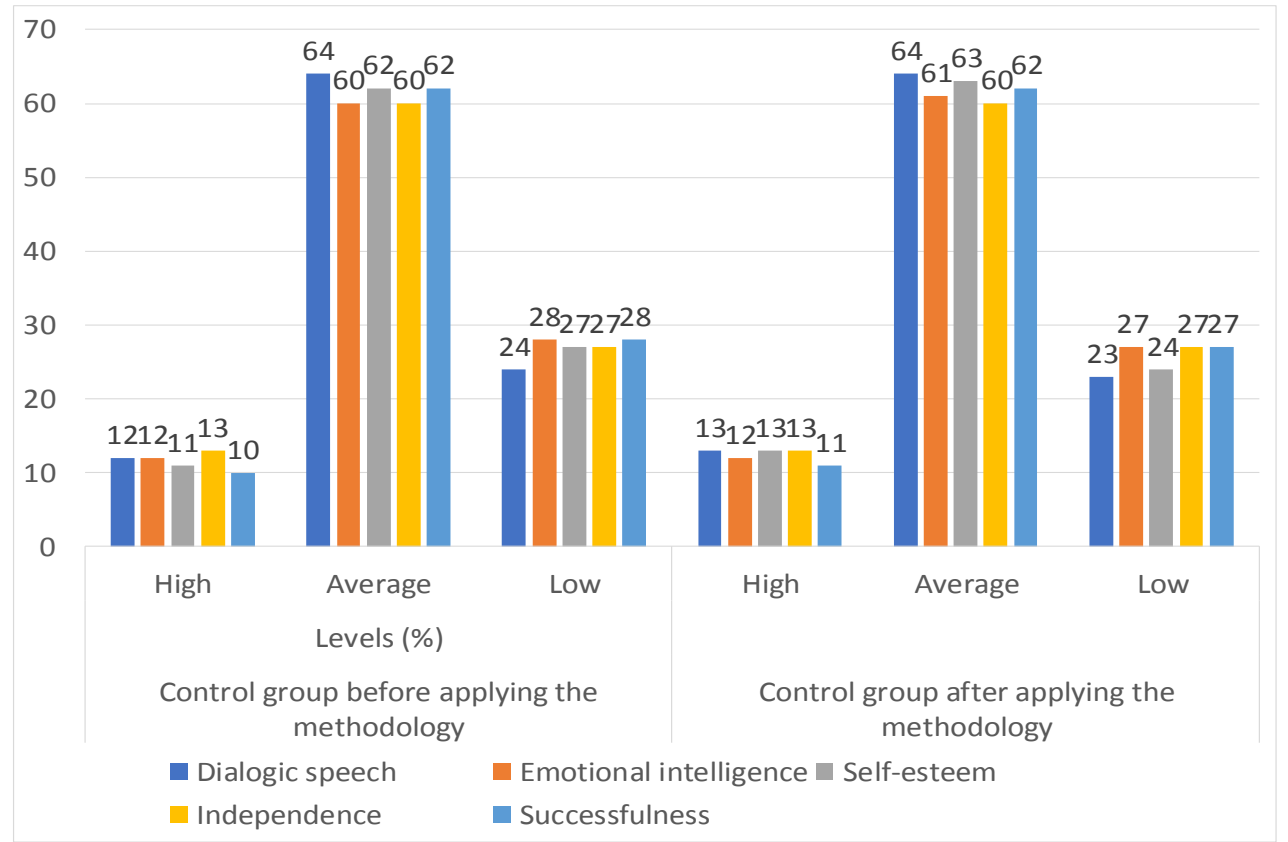

Fig. 3. Dynamics of positive socialization and development levels of dialogic speech of preschool children in the control group (initial and final diagnostics).

\section{Discussion}


A survey of children from the experimental group after conducting the formative research, at which the proposed authorial program of positive socialization and dialogue speech development was used in the educational process of preschool educational organizations, suggests that positive changes in the levels of the studied parameters in the experimental group are more evident than those for children in the control group. The growth in indicators of positive socialization and development of dialogic speech in the experimental group is more significant. The percentage of children with a high level of positive socialization and development of dialogic speech has increased after the formative stage of experimental work. At that, due to the program implemented in the educational process of the experimental group at the formative stage of the study, the percentage of children with an average level of the studied characteristics has increased. This was due to children who at the control stage of the study showed a low level of positive socialization and development of dialogic speech. Also, in the experimental group, the percentage of children with low indicators of positive socialization and level of dialogic speech development has decreased.

Statistical comparison based on the Student's t-test (calculated using the SPSS Statistics Program) has confirmed that the differences at the control stage of the experiment between the experimental and control groups were statistically significant with the significance level $=0.05$. This suggests that these differences are due to the implementation of a program for positive socialization of older preschool children in the development of dialogic speech.

The obtained results indicate that the set tasks have been completed, and the program can be recommended to be used for positive socialization of older preschoolers in the course of developing their dialogic speech at preschool educational organizations.

\section{Conclusion}

In the course of experimental work, it has been proved that the levels of positive socialization in older preschoolers increase in the course of developing skills and abilities of dialogic speech that is accompanied by the simultaneous success of all training and upbringing components. The parameters used to indicate positive socialization increase as the child develops new speech, etiquette, and behavioral skills, as well as dialogic speech skills.

Thus, the process and level of positive socialization of older preschoolers will be more successful in case of providing the necessary psychological and pedagogical conditions that would contribute to the effectiveness of the dialogic speech developing process.

\section{References}

1. Ye.N. Volkova, T.V. Vereitinova, I.V. Volkova, O.S. Mikhalyuk, Bulletin of the Minin University, 2, 1-9 (2016)

2. E. Šaras, L. Perez-Falkner, Sociological Perspectives on Socialization. Oxford Bibliographies in Sociology (Oxford University Press, Oxford, 2018)

3. J.G. Smetana, J. Robinson, W.M. Rote, Socialization in adolescence, in Handbook of socialization: Theory and research, 60-84 (Guilford Press, New-York, 2015)

4. M.M. Alekseeva, V.I. Yashina, Methods of speech development and teaching the native language of preschoolers (Publishing Center Academiya, Moscow, 2000)

5. A.I. Savenkov, Modern foreign psychology, 7(2), 7-15 (2018)

6. A. I. Savenkov, S. I. Karpova, E. I. Sukhova, Psychology (Savannah, Ga.), 55(2), $74-$ 84 (2018) 
7. Z.V. Parkhimovich, T.D. Savenkova, Bulletin of the Moscow City University. Series: Pedagogy and Psychology, 2(44), 107-120 (2018).

8. T.D. Savenkova, Development of social intelligence of pre-schoolers (Yurayt, Moscow, 2020)

9. M. Anwer, N.I. Malik, A. Maqsood, G. Rehman, Pakistan Journal of Psychology, 48(2), 3-20 (2017)

10. Ye.V. Aladatova, A.M. Nekhorosheva, T.P. Shestakova, Speech development of senior preschool children through speech trainings, in Pedagogy: traditions and innovations: materials of the VIII International scientific conference, January 2017, Chelyabinsk, Russia (Dva Komsomoltsa, Chelyabinsk, 2017)

11. T.I. Babaeva, O.V. Akulova, O.V. Solntseva, Integrated educational program of preschool education Childhood (Doshkolnaya pedagogika, Saint Petersburg, 2014)

12. O.A. Bizikova, Development of dialogical speech of preschoolers in the game (Scriptorium 2003, Moscow, 2008)

13. V.V. Gerbova, Speech development in kindergarten (Mosaika-Sintez, Moscow, 2009)

14. T.G. Fedorenko, The problem of effective organization of the process of communicative development of preschool children. Modern vectors of education development: current problems and promising solutions: collection of scientific papers of the XI International scientific and practical conference: in 2 parts, 712-718 (Moscow, 2019)

15. J.D. Mayer, P. Salovey, Electronic Journal of Research in Educational Psychology, 15(6 (2)), 421-436 (2008) 